Journal of Composite Materials

\title{
Prediction of failure envelopes and stress strain curves of fiber composite laminates under triaxial loads: comparison with experimental results
}

\begin{tabular}{|c|c|}
\hline Journal: & Journal of Composite Materials \\
\hline Manuscript ID: & $\mathrm{JCM}-12-0327 . \mathrm{R} 1$ \\
\hline Manuscript Type: & Special Issue: 2BWWFE \\
\hline Date Submitted by the Author: & 20-Jun-2012 \\
\hline Complete List of Authors: & Ye, Jianqiao ; Lancaster University, Engineering \\
\hline Keywords: & $\begin{array}{l}\text { Composite laminates, Failure criterion, Laminate strength, Stress strain } \\
\text { behaviour }\end{array}$ \\
\hline Abstract: & $\begin{array}{l}\text { This paper represents the authors' contribution to Part B of the Second } \\
\text { World Wide Failure Exercise (WWFE-II), in which the failure predictions and } \\
\text { stress strain curves of twelve test cases are compared with experimental } \\
\text { data. The paper briefly reviews the methodology presented in WWFE-II } \\
\text { Part A, which includes a semi-analytical stress analysis model and } \\
\text { Christensen ( } 2007,2008 \text { )'s failure criteria. A further development in this } \\
\text { paper is to introduce a new failure criterion developed also by Christensen } \\
\text { (2009) and the application of the criterion in conjunction with the stress } \\
\text { model. These failure criteria have no adjustable parameters and only } \\
\text { depend upon a minimal number of measurable failure properties. } \\
\text { Comparisons between the theoretical predictions using different criteria } \\
\text { and the experimental results provided by the WWFE-II organizers are } \\
\text { shown in diagrams. It appears that Christensen (2008)'s failure criteria } \\
\text { predict the failure strength satisfactorily in most of the test cases. } \\
\text { Christensen (2009)'s Polynomial Invariants theory compares also well with } \\
\text { the experimental results. However, the layup-dependent strength } \\
\text { properties required in the criterion are sometimes very difficult to evaluate } \\
\text { without performing experimental tests. }\end{array}$ \\
\hline
\end{tabular}

\section{SCHOLARONE $^{\text {m }}$ \\ Manuscripts}




\title{
Copyright $^{\circledR}$ WWFE-II 2012
}

\section{Prediction of failure envelopes and stress strain curves of fiber composite laminates under triaxial loads: comparison with experimental results}

\author{
Daxu Zhang ${ }^{\mathrm{a}}$, Lihua $\mathrm{Xu}^{\mathrm{b}}$ and Jianqiao $\mathrm{Ye}^{\mathrm{c}^{*}}$ \\ ${ }^{\mathrm{a}} \mathrm{School}$ of Naval Architecture, Ocean and Civil Engineering, \\ Shanghai Jiao Tong University, Shanghai, China \\ ${ }^{\mathrm{b}}$ School of Civil Engineering, Wuhan University, Wuhan, China \\ ${ }^{c}$ Department of Engineering, Lancaster University, Lancaster LA1 4YR, UK
}

\begin{abstract}
This paper represents the authors' contribution to Part B of the Second World Wide Failure Exercise (WWFE-II), in which the failure predictions and stress strain curves of twelve test cases are compared with experimental data. The paper briefly reviews the methodology presented in WWFE-II Part A, which includes a semi-analytical stress analysis model and Christensen's $(2007,2008)$ failure criteria. A further development in this paper is to introduce a new failure criterion developed also by Christensen (2009) and the application of the criterion in conjunction with the stress model. These failure criteria have no adjustable parameters and only depend upon a minimal number of measurable failure properties. Comparisons between the theoretical predictions using different criteria and the experimental results provided by the WWFE-II organizers are shown in diagrams. It appears that Christensen's (2008) failure criteria predict the failure strength satisfactorily in most of the test cases. Christensen's (2009) Polynomial Invariants theory compares also well with the experimental results. However, the layup-dependent strength properties required in the criterion are sometimes very difficult to evaluate without performing experimental tests.

Key words: Composite laminates; Failure criterion; Laminate strength; Stress strain behaviour
\end{abstract}

\section{Introduction}

In our paper (Ye and Zhang, 2012) submitted to Part A of the Second World Wide Failure Exercise (WWFE-II), an approach for predicting stress-strain response and failure envelopes of composite

\footnotetext{
* Corresponding author. E-mail address: j.ye2@lancaster.ac.uk
} 
laminates was presented. For the stress analysis, a semi-analytical method, extended from the authors' previous work (Zhang et al., 2006a, 2006b, 2007, and 2008) was proposed to evaluate three-dimensional stresses and displacements in general angle-ply laminates subjected to triaxial loads and uniform temperature changes. Christensen's stress-based failure criteria (Christensen, 2007 and Christensen, 2008) were adopted to predict failure of matrix or lamina. Predictions have been made for the ten test cases specified by the organizers of WWFE-II (Kaddour and Hinton, 2007), by using the stress analysis model and/or Christensen's failure criteria. Predictions from Part A were made 'blindly' since no experimental results for the test cases were given to the participants.

The present paper represents our contribution to Part B of the exercise. The main objective is to assess the fidelity of the methodology in Part A by comparing the theoretical predictions with the experimental data, provided to the contributors in Part B by the organizers. In addition to the failure criteria used in Part A of the exercise, the newly developed Polynomial Invariants failure criterion (Christensen, 2009), which was not available when the work of Part A was carried out, is adopted to obtain the failure envelopes of test cases, 10 and 11. The accuracy of the predictions and the possible reasons to cause the difference between predictions using different theories are discussed.

\section{Brief description of the theory in Part A}

\subsection{Stress analysis using the state space method}

The state space method (Ye and Zhang, 2012) was developed to evaluate three-dimensional stresses and displacements in general angle-ply laminates subjected to triaxial loads and uniform temperature changes. A linear stress-strain behaviour and generalized plane strain deformation was assumed in the model.

The state space equation (Eq. (8) in Ye and Zhang (2012), for a lamina, which is a first order partial differential equation, was derived by using the constitutive stress-strain equations for orthotropic materials, the equilibrium equations, and the compatibility conditions. The state space equation governs the stress and displacement fields of the lamina. By using assumed displacement functions, which are further expressed in the form of Fourier series expansions, the numerical solutions of the state space equation can be determined. The solution of the state space equation ultimately yields displacements and stresses as functions of the through-thickness coordinate.

For a laminated composite, it was assumed that it is divided into a large number of thin sub-layers 
that can be thinner than a material layer of the composite. Thus, two types of material interfaces are distinguished in the laminate; the fictitious interfaces that separate sub-layers with the same material properties and the real ones that separate sub-layers composed of different materials. The state space equation of a lamina can be applied to each sub-layer. After obtaining the state space equations of all individual sub-layers and with appropriate continuity requirements imposed at all the real and fictitious interfaces, the state space equation for the entire laminate can be formulated. The solution (Eq (19) in Ye and Zhang, Part A) of the state space equation of a laminate can be finally determined by introducing the boundary conditions at the top and bottom faces. Since a linear stress-strain relation was used, the state of stresses under triaxial loads can then be determined by superimposing the stresses due to in-plane loads and those obtained separately for through thickness loading.

Comparing with other analytical solutions of laminated composites (Noor and Burton, 1990), the current model does not introduce any pre-assumptions on the through-thickness stress distribution, which enables the continuity of both displacements and stresses at the material interfaces be fully satisfied. This feature provides accurate predictions to the through-thickness stresses that are also vital in a delamination analysis. Since the recursive formulation (Eq. (18) in Ye and Zhang, Part A) is used to derive the state equation of the laminate, the dimension of the final state equation does not depend on the number of layers of the laminate. Consequently, this method is particularly suitable to compute stresses and carry out failure analysis of laminates with a large number of layers. This advantage makes it possible to use the state space method in practical design of multi-layered composites. A MATLAB computer code was developed to carry out the stress analysis, which requires the input of lamina properties, laminate dimensions, lay-ups, and loading conditions. The output of the code includes three-dimensional stress, and strain and displacement fields of the laminates.

The current stress analysis model, the state space method, is a 3D approach, in which all the 3D stress components are fully taken into account, including the interlaminar normal and shear stresses. Due to that a generalised plane strain deformation is assumed, the stresses are functions of both the through-thickness coordinate, $z$ and the in-plane coordinate $x$. For the test cases in the exercise, the interlaminar normal stress is constant since the applied loads are uniformly distributed and no discontinuity of boundary conditions, e.g. free edges or matrix cracks, is considered. Currently, the stress model has difficulties in prescribing out-of-plane shear to the boundary surfaces, but it is capable of calculating all stresses, including interlaminar shear stresses induced by other conditions, 
e.g. the effects of free edges or transverse matrix cracks.

\subsection{Failure criteria}

Christensen's failure criteria (Christensen, 2007; 2008) were adopted to predict the failure envelopes of the test cases. The criteria include forms for both isotropic and anisotropic fibre reinforced composite materials. The form for fibre composite materials requires six strength properties at lamina level, where the strengths are based on a homogenisation of fibres and matrix. During the course of the research described in this paper, evidence described in the aftermentioned section of Matrix Controlled Failure suggested that the number of the strength properties could be reduced to five. Since the material properties used in the present stress analysis are also homogenized properties, this makes it feasible to predict failure of composite laminates by combining the stress analysis model and Christensen's failure criteria. Christensen's failure criteria adopted in the current work were developed for highly anisotropic materials, carbon-polymer composites, in which the ratio of the longitudinal stiffness to the transverse stiffness of a lamina is normally greater than ten. Although for glass-polymer composites, in which this ratio is usually less than ten, the failure criteria for carbon-polymer composites will be used because no failure criteria for glass-polymer composites is available in the current Christensen's failure theory.

For the isotropic material, the failure criterion (Christensen, 2007) is as follow,

$$
\begin{aligned}
& \left(\frac{1}{\bar{T}}-\frac{1}{\bar{C}}\right)\left(\sigma_{x x}+\sigma_{y y}+\sigma_{z z}\right)+ \\
& \frac{1}{\overline{T C}}\left\{\frac{1}{2}\left[\left(\sigma_{x x}-\sigma_{y y}\right)^{2}+\left(\sigma_{y y}-\sigma_{z z}\right)^{2}+\left(\sigma_{z z}-\sigma_{x x}\right)^{2}\right]+3\left(\sigma_{x y}^{2}+\sigma_{y z}^{2}+\sigma_{x z}^{2}\right)\right\} \leq 1
\end{aligned}
$$

where $\bar{T}$ and $\bar{C}$ are uni-axial tensile and compressive strengths, respectively. The failure criterion is only valid for $\bar{T}$ less than or equal to $\bar{C}$, and does not apply or give any information when the uni-axial tensile strength is greater than compressive strength for a homogeneous and isotropic material . When the tensile strength of a material is significant smaller than its compressive strength, Christensen theory requires that an additional fracture criterion must also be satisfied to prevent brittle failure. Thus

$$
\begin{array}{ll}
\text { if } & \bar{T} \leq \frac{\bar{C}}{2} \\
\text { then } & \sigma_{I} \leq \bar{T}
\end{array}
$$


where $\sigma_{I}$ is the largest principal stress at a point.

An isotropic material can be conventionally characterised as either ductile or brittle. Christensen (2007) defined the material's ductile-brittle behaviour for a particular stress state by using the $\bar{T} / \bar{C}$ variation. For uniaxial tension, a material is found to be ductile when $\bar{T} / \bar{C}>0.5$ and be brittle when $\bar{T} / \bar{C}<0.5$. A comprehensive discussion of ductility levels of an isotropy can be found in Christensen (2010).

Equation (1a) defines the general theory for both ductile and brittle materials. Equations (1b) and (1c) distinguish the failure mode, fracture type brittle failure from a yielding type ductile failure. When $\bar{T}=\bar{C}$ the criterion (1a) becomes the Von Mises yield criterion (von Mises, 1913), and the fracture criterion (1c) is inoperative because of (1b) (Christensen, 2007). Equation (1b) defines the condition for brittle materials by the two failure properties, $\bar{T}$ and $\bar{C}$. The fracture part, equation (1c), also has historical antecedents as the maximum stress form (Christensen, 2007).

The failure criteria for the anisotropic fiber composite lamina are defined by decomposing the failure modes into matrix controlled failure and the fiber controlled failure as:

(1) Matrix Controlled Failure

$$
\begin{aligned}
\left(\frac{1}{\bar{T}_{22}}-\frac{1}{\bar{C}_{22}}\right)\left(\sigma_{22}+\sigma_{33}\right)+ & \frac{1}{\bar{T}_{22} \bar{C}_{22}}\left(\sigma_{22}+\sigma_{33}\right)^{2} \\
& +\frac{1}{\bar{S}_{23}^{2}}\left(\sigma_{23}^{2}-\sigma_{22} \sigma_{33}\right)+\frac{1}{\bar{S}_{12}^{2}}\left(\sigma_{12}^{2}+\sigma_{13}^{2}\right) \leq 1
\end{aligned}
$$

where $\bar{S}_{23}^{2} \geq \bar{T}_{22} \bar{C}_{22} / 4$ must be satisfied in order to have real roots from the criterion.

Equation (2a) has been used in the Part A paper to determine the failure envelopes for some test cases. Since the failure criteria are sensitive and in some cases extremely sensitive to the values of the failure properties, especially $\bar{S}_{23}$, the uncertainty in the test values for $\bar{S}_{23}$ may make a significant difference in the predictions. In private communication with Professor Christensen (Christensen, 2010), he pointed out that the failure criterion in Eq. (2a) was extremely sensitive to the values of $\bar{S}_{23}$ relative to those of $\bar{T}_{22}$ and $\bar{C}_{22}$. In fact, the sensitivity is so great that it places impossible demands on the experimental accuracy in determining these three properties. Knowing that in isotropic 
materials the shear strength can be expressed in terms of the tensile and compressive strengths, Christensen (2011) postulated that the shear property, $\bar{S}_{23}$, was not physically independent of $\bar{T}_{22}$ and $\bar{C}_{22}$, but that they were interrelated. Using micromechanics, a relationship between $\bar{S}_{23}$ and $\bar{T}_{22}$ and $\bar{C}_{22}$ was proposed for typical epoxy resin and carbon fiber properties. Christensen (2011) shows that this relationship between these three matrices controlled failure properties is given by the relation

$$
\bar{S}_{23}^{2}=\frac{2}{7} \bar{T}_{22} \bar{C}_{22}
$$

The shear property test is usually more difficult to implement than the uni-axial properties tests, and therefore the accuracy of experimental values of uni-axial tensile and compressive strengths is expected to be higher than that of the shear strength. Considering that $\bar{T}_{22}$ and $\bar{C}_{22}$ are likely to be determined with a greater degree of certainty than is $\bar{S}_{23}$, in all cases to follow the $\bar{T}_{22}$ and $\bar{C}_{22}$ properties will be taken from the data table, but $\bar{S}_{23}$ will be determined by Eq. (2b).

(2) Fiber Controlled Failure

$$
-\bar{C}_{11} \leq \sigma_{11} \leq \bar{T}_{11}
$$

In relations (2) and (3), $\bar{T}_{11}, \bar{C}_{11}, \bar{T}_{22}, \bar{C}_{22}$ are the respective tensile and compressive strengths in the fiber and transverse directions; $\bar{S}_{23}$ is the transverse shear strength and $\bar{S}_{12}$ are the longitudinal shear strength.

All the material strengths appearing in Equations (1), (2) and (3) are obtained from uniaxial tests and are positive quantities.

\section{The latest Christensen's Failure criteria}

In Part A, laminate failure was predicted by using the failure criteria at the lamina level. The damage of a laminate initiates from the first lamina failure and the damage develops when more loadings or extra stresses take place. When the damage accumulates to a level, where all the load carrying laminae in a laminate fail, the laminate reaches the ultimate load, at which the laminate can no longer sustain load. This lamina level-based failure prediction of a laminate is defined as 
progressive damage in Christensen (2009), which indicates the damage process from the local failures at the lamina level to the global ultimate failure at the laminate level. The lamina level failures can be types of either matrix controlled or fibre controlled, i.e. equations (2) and (3). They contribute to the laminate level failure in a progressive way. In order to use the lamina level failure criteria to predict the failure of a multi-layer laminate, a stress analysis needs to be performed to evaluate the damage sequence of different laminae. The state space method, briefly introduced in 2.1, can used to determine the stress distribution in laminates with general lay-ups. In the exercise, a stress analysis was carried out in test cases 8,9 and 12 .

A laminate level failure criterion, Polynomial Invariants, was proposed by Christensen (2009). The same methodology used to develop the failure criterion for isotropic materials was adopted to derive the Polynomial Invariants failure criteria. First, take a polynomial expansion in the stress invariants, then truncate the expansion at second degree terms and express that as the possible failure criterion, and finally evaluate the failure parameters by calibrating the criterion with the strength properties. The Polynomial Invariants failure criteria for the in-plane failure mode are given by

(a) quasi-isotropic laminates

$$
\left(\frac{1}{T}-\frac{1}{C}\right)\left(\sigma_{11}+\sigma_{22}\right)+\frac{1}{T C}\left(\sigma_{11}+\sigma_{22}\right)^{2}+\frac{1}{S^{2}}\left(\sigma_{12}^{2}-\sigma_{11} \sigma_{22}\right) \leq 1
$$

where $T$ and $C$ are the in-plane uni-axial tensile and compressive strengths and $S$ is the in-plane shear strength; and

(b) orthotropic laminates

$$
\left(\frac{1}{T_{11}}-\frac{1}{C_{11}}\right) \sigma_{11}+\frac{1}{T_{11} C_{11}} \sigma_{11}^{2}+\left(\frac{1}{T_{22}}-\frac{1}{C_{22}}\right) \sigma_{22}+\frac{1}{T_{22} C_{22}} \sigma_{22}^{2}+\lambda_{12} \sigma_{11} \sigma_{22}+\frac{\sigma_{12}^{2}}{S_{12}^{2}} \leq 1
$$

where, $T_{11}, C_{11}, T_{22}, C_{22}$ are the respective tensile and compressive strength in two in-plane directions; $S_{12}$ is the in-plane shear strength. The property $\lambda_{12}$ can be determined (not uniquely) as

$$
\lambda_{12}=-\frac{2}{3 \sqrt{T_{11} C_{11} T_{22} C_{22}}}
$$

Eq. (4b) is reduced to the quasi-isotropic Eq. (4a) when $S_{12}^{2}=(3 / 8) T C$ and $\lambda_{12}$ takes the form of Eq.(4c). (Christensen, 2009). A quasi-isotropic laminate is a balanced and symmetric laminate, which displays in-plane isotropic behaviour, e.g. $\left(0^{\circ} \pm 60^{\circ}\right)_{\mathrm{s}}$ and $\left(0^{\circ} / \pm 45^{\circ} / 90^{\circ}\right)_{\mathrm{s}}$ laminates. An orthotropic laminate has three mutually perpendicular planes of property symmetry, e.g. $\left(0^{\circ} / 90^{\circ}\right)_{\mathrm{s}}$. 
The failure criterion for out-of-plane failure mode, delamination, is

$$
\left(\frac{1}{T_{33}}-\frac{1}{C_{33}}\right) \sigma_{33}+\frac{1}{T_{33} C_{33}} \sigma_{33}^{2}+\frac{1}{S_{23}^{2}}\left(\sigma_{23}^{2}+\sigma_{31}^{2}\right) \leq 1
$$

where, $T_{33}$, and $C_{33}$ are the through thickness tensile and compressive strength and $S_{23}$ is the interlaminar shear strength. Eq.(4d) is intended for through thickness tension, compression and shear at all pressure levels. Equation (4d) indicates that delamination is associated only with tensile stress if there is no through shear stress. Otherwise, both compressive and tensile stresses affect the delamination process.

An important feature of the polynomial invariants method is that it implicitly includes the interactive effects of different damage modes at intra-lamina levels, which has not been considered in the progressive damage criteria.

\section{Comparison of predictions and experimental results}

WWFE-II Part A supplied the details of 12 test cases, in which the material properties, laminate lay-ups and loading configurations are all defined. The participants were requested to predict failure envelopes or stress-strain curves of one epoxy matrix, six unidirectional laminae, two balanced angle-ply laminates, one quasi-isotropic laminate, and two orthotropic laminates. For completeness, a summary of the test cases and material properties (Kaddour and Hinton, 2007) used in the predictions are shown in Tables 1 and 2. Apart from the data listed in Table 2, nonlinear shear and transverse compressive stress-strain curves for the unidirectional laminae were also provided in Kaddour and Hinton (2007). Since the current model employs a linear elastic assumption, only the initial material properties have been used in the predictions. Experimental results of the 12 test cases in Part A are provided in WWFE-II Part B (Hinton and Kaddour; 2009). A comparison of the theoretical predictions with the test data is presented in this section.

\subsection{Test Case 1}

In this test case, the failure envelope of an epoxy polymer material, MY750, subject to triaxial loading (with $\sigma_{\mathrm{y}}=\sigma_{\mathrm{z}}$ ), has been predicted in Part A. A comparison of the theoretical predictions and the experimental data (Hine et al., 2005) for this test case is shown in Figure 1. As expected, the provided test data, which are for the case of uni-axial loading in the $x$ direction, lie exactly on the predicted 
envelope. When the material is subject to compression in the y- and z-directions, the theoretical model slightly over-predicted the compressive strength. The failure envelope is open in the third quadrant, which satisfies the condition that isotropic material does not fail under compressive hydrostatic stress. In general, there is a good agreement between the theoretical predictions and the experimental data for this test case.

\subsection{Test Cases 2, 3 and 4}

Predictions for a unidirectional T300/PR319 lamina, under triaxial and in-plane shear loading, have been presented in Part A using Christensen's (2008) failure criterion. The aforementioned adjustment has been made in these test cases. Figures 2, 3 and 4 show comparisons of theoretical predictions and test data (Shin and Pae, 1992a; 1992b) for shear failure strength, shear failure strain and shear stress-strain curves, respectively. Both the original predictions ( $\bar{S}_{23}=45 \mathrm{MPa}$ from the organizers) in Part A and the new refined results $\left(\bar{S}_{23}=37.8 \mathrm{MPa}\right.$ from eq.2b) are presented. It can be seen that under hydrostatic pressure, the new predicted failure envelopes correlate with the test data much better than the original one. However, the overall shapes of both failure envelopes do not match the plateau of the test data from $0^{\circ}$ tubes. In figures 2 and 3, the results obtained by using $\bar{S}_{23}=34 \mathrm{MPa}$ are also presented to demonstrate the extreme sensitivity of the failure envelopes to the values of the shear strength, as being discussed in the paragraph above Eq.(2b).

In these figures, Christensen (2008) represents the original predictions from Part A of the exercise by using equations (2a) and (3); Christensen (2008, refined) is associated with the results using equation (2b) to calculate $\bar{S}_{23}$, which is a refinement of the original criteria; Christensen (2008, reference) denotes results using an arbitrary value of $\bar{S}_{23}$ to demonstrate the high sensitivity of failure envelopes to the value of $\bar{S}_{23}$.

For the experimental results, data from the $90^{\circ}$ tubes are more representative because the exercise has requested the in-plane shear strength, $\tau_{12}$, whereas the results from the $0^{\circ}$ tubes represent the transverse shear strength, $\tau_{13}$. It can be seen from Figures 2 and 3 that both predictions match the test data reasonably well when the hydrostatic pressure is low.

Although a hydrostatic pressure of $600 \mathrm{MPa}$ is required for the test case 4, the current theory predicts the failure at the value of $367 \mathrm{MPa}$ hydrostatic pressure, which is much lower than the 
requested value. Consequently half of the predicted maximum hydrostatic strength, 183.5 MPa is used in figure 4 to predict the shear stress strain curve, where the material has the maximum shear strength (see Fig.2 or 3). In general, due to the linear elastic assumption, the predictions agree with the test data well before the nonlinearity occurs at $\gamma_{12} \approx 8 \%$.

\subsection{Test Cases 5, 6 and 7}

Failure envelopes of three uni-directional laminae, E-glass/MY750, S-glass/epoxy, and A-S carbon/epoxy, under triaxial stresses have been predicted in Part A using Christensen's (2008) theory. The aforementioned adjustments have been made to test cases 5 and 7, in which $\bar{S}_{23}$ is taken as 40.7 MPa and 40.4 MPa, respectively. Comparisons of the theoretical predictions and test data (Hine et al., 2005; Zinoviev et al., 1999; Zinoviev et al., 2001; Wronski and Parry, 1982; Parry and Wronski, 1981; Parry and Wronski, 1982) are shown in Figures 5, 6 and 7, respectively. In comparison with the test results, it appears that in Figures 5 and 7 the original predictions based on the $\bar{S}_{23}$ provided by the organizer underestimated the compressive failure strengths, while the new results using the computed $\bar{S}_{23}$ from Eq.(2b) improve the predictions significantly. In Figure 6, reasonable correlation between the theoretical and the test results is observed. The experimental data suggests that there is some degree of interaction between transverse matrix and longitudinal fibre compressive strength, which is not captured by the failure criteria.

\subsection{Test Cases 8 and 9}

The stress failure envelope and stress strain curves of the $\left(+35^{\circ} /-35^{\circ}\right)_{\mathrm{s}}$ E-glass/MY750 laminate subject to triaxial normal stresses (with $\sigma_{\mathrm{x}}=\sigma_{\mathrm{z}}$ ) have been presented in Part A. The failure of this symmetric angle-ply laminate was predicted by using Christensen's criteria (2008). For test case 8, a new prediction has been made by replacing $\bar{S}_{23}=50 \mathrm{MPa}$ by $\bar{S}_{23}=40.7 \mathrm{MPa}$ from Eq.(2b). A comparison of the experimental results (Liu et al., 2005; Kaddour et al., to be published) with the theoretical predictions are shown in Figures 8 and 9. Figure 8 shows again the use of Eq.(2b) for $\bar{S}_{23}$ improves the failure strength predictions significantly. For the stress strain curves in Figure 9, theoretical predictions have good correlations with the test data before severe nonlinearities appear in the experimental results.

\subsection{Test cases 10 and 11}


In Part A, due to the difficulties in applying out-of-plane shear to the analytical laminate model, the specified loading conditions ( $\sigma_{\mathrm{z}}$ vs $\tau_{\mathrm{zy}}$ ) for test cases 10 and 11 were replaced by applying triaxial loading. The specified loading conditions $\left(\sigma_{\mathrm{z}}\right.$ vs $\tau_{\mathrm{zy}}$ ) can be modelled now by using Christensen's (2009) Polynomial Invariants failure criterion, which was not available when the work in Part A was carried out. This is because the Polynomial Invariants is a laminate level failure criterion and therefore no stress analysis at lamina level is required to evaluate the laminate failure envelope.

A comparison of the experimental results (De Teresa et al.; 2001 and 2004) and the theoretical predictions is shown in Figures 10 and 11. Since no through-thickness compressive strength is given in De Teresa et al., (2001 and 2004), three compressive strengths obtained from Kaddour et al., (to be published) are used to predict the failure envelopes. In general, the predictions obtained using compressive strength, $\mathrm{C}_{33}=1184 \mathrm{MPa}$, agrees better with the experimental results than those using the other two compressive strengths. The theoretical predictions show that significant reduction in shear strength occurs as the through thickness compression increases, though this was not observed from the limited experimental data.

\subsection{Test case 12}

The laminates used in test cases 11 and 12 are identical. In Part A, stress-strain curves $\left(\sigma_{\mathrm{z}}-\varepsilon_{\mathrm{z}}, \sigma_{\mathrm{z}}-\varepsilon_{\mathrm{x}}\right.$, and $\sigma_{\mathrm{z}}-\varepsilon_{\mathrm{y}}$ ) for the laminate under triaxial loading were predicted using the lamina level criteria (Christensen, 2008). In Part B, as the laminate level failure criteria Christensen (2009) is employed in test case 11, the new strength obtained is then applied to test case 12. Although predictions of stress-strain curves $\left(\sigma_{\mathrm{z}}-\varepsilon_{\mathrm{z}}, \sigma_{\mathrm{z}}-\varepsilon_{\mathrm{x}}\right.$, and $\left.\sigma_{\mathrm{z}}-\varepsilon_{\mathrm{y}}\right)$ for the $\left(0^{\circ} / 90^{\circ}\right)_{\mathrm{s}}$ IM7/8551-7 laminate under through-thickness pressure were required in Part A, no experimental data was provided for the $\left(0^{\circ} / 90^{\circ}\right)_{\mathrm{s}}$ layup in Part B. Instead experimental results obtained by Kaddour et al., (to be published) on quasi-isotropic $\left(45^{\circ} / 0^{\circ} /-45^{\circ} / 90^{\circ}\right)_{\mathrm{ns}}$ layup laminates made of similar materials were suggested as a guidance. A comparison of these experimental results and the theoretical predictions is shown in Figures 12. It can be seen that slopes of the predicted curves match the initial stiffness of test data very well, but the failure strength and nonlinearity of the experimental results cannot be captured.

\section{Discussion and conclusions}

The semi-analytical stress analysis method and Christensen's $(2007,2008)$ failure criteria presented in WWFE-II Part A were briefly reviewed in this paper. The newly developed Christensen's (2009) 
Polynomial Invariants was introduced to deal with test cases 10 and 11. Numerical tests have shown that the matrix controlled failure mode is extremely sensitive to the relative values of through-thickness shear strength. In order to reduce the effect of uncertainty in the test value of the shear strength, a new result based on micromechanics for determining the strength was derived and used in the calculation.

The theory predicted an open envelope for the polymer material (Test Case 1) and closed envelopes for the composites (Test Cases 5 and 8), which suggests that polymer material is much stronger than the composites under hydrostatic compression, due to that fact that composite is highly anisotropic and this causes large distortions even under hydrostatic pressure.

From the comparison between the theoretical and the experimental results in test cases 2-9, it appears that the predictions using Christensen's (2008) lamina failure criterion met the test results reasonably well for most cases, though they were in general conservative. One of the reasons is that during a test, the matrix may have already failed as predicted by the matrix controlled model criterion, while the pressure holds it all together and gives overestimated values for apparent failure envelopes. It is similar to a granular material that is under pressure and gives a very good imitation of being a real cohesive material for some conditions. Future tests are needed to verify this observation.

Christensen's (2009) Polynomial Invariant theory, which is a laminate level criterion, compared fairly well with the experimental data in test cases 10 and 11. Polynomial Invariant implicitly contains the interactive effects between damage at intra-lamina and inter-lamina levels, including the effects of the lamina stacking sequence. However, the layup-dependent strength properties required in the criterion are sometimes very difficult to evaluate without performing comprehensive experimental tests.

The matrix controlled failure criterion, Equation (2), is very sensitive to the through-thickness shear strength. After the small adjustments to the shear strength of some UD laminates, the lamina level failure criterion gave reasonable predictions of the failure envelopes in most cases. However, it is still not known if good correlation can be achieved in a wide variety of composite materials under complex loading conditions. In general, the development of failure criteria for composite materials is not completed and the current theory needs further development in many aspects, e.g. nonlinear material properties, material discontinuities, damage evolution, and interactions of failure modes.

The current theory provides good correlation with test data when the composite is under low 
pressure, but a relatively large deviation under high pressure. After the adjustment, the largest percentage difference between the predictions and the test data is about $100 \%$ in test case 2 . Since constant material properties have been used in the stress analysis, the predicted stress-strain curve does not capture the nonlinearity in test cases 9 and 12. In order to overcome this problem, a nonlinear stress analysis needs to be developed in the future.

There is no doubt that WWFE-II provides a very good opportunity to assess the current theory. The test cases defined in the exercise and experimental data are very valuable to validate many aspects of the current model. The experience and knowledge gained from the exercise are useful to further develop the model.

\section{Acknowledgment:}

The authors are grateful to Prof. R. Christensen of Stanford University for reading of and providing constructive comments on the paper. This paper could not be completed without his significant contribution, including providing his unpublished work on the shear strength. The authors are also grateful to QinetiQ for providing technical supports and test results.

\section{References}

Christensen, R. M., 2007. II. Yield and Failure Criteria for Isotropic Materials. $<$ http://www.failurecriteria.com/Media/Yield_and_Failure_Criteria_for_Isotropic_Materials. $\operatorname{pdf}>$

Christensen, R. M., 2008. III. Failure Criteria for Anisotropic Fiber Composite Materials. $<$ http://www.failurecriteria.com/Media/Failure_Criteria_for_Anisotropic_Fiber_Composite_ Materials.pdf $>$

Christensen, R. M., 2009. V. Failure of Fibre Composite Laminates - Progressive Damage and Polynomial Invariants.

$<$ http://www.failurecriteria.com/Media/Failure_of_Fiber_Composite_Laminates-_Progressiv e_Damage_and_Polynomial_Invariants.pdf $>$

Christensen, R. M., 2010. VII. The Ductile/Brittle Transition, Gaging Ductility Levels < http://www.failurecriteria.com/Media/Ductile_Brittle_Transition_Gaging_Ductility_Levels. $\operatorname{pdf}>$

Christensen, R. M., 2011. IX. Micromechanics Failure Analysis

$<$ http://www.failurecriteria.com/Media/Micromechanics_Failure_Analysis.pdf > 
Christensen, R. M., 2010. Experimental Accuracy and Sensivity of Shear Strength, S23, in Matrix Controlled Failure Criterion for Anisotropic fibre Composite Lamina. Private communication. November 2010.

DeTeresa S J, Dennis C. Freeman And Groves S E 'The Effects of Through-thickness Compression on the Interlaminar Shear Response of Laminated Fiber Composites', J Compos Mater, V 38, No. 8, pp681-697, 2004.

DeTeresa S. J, L. M. Allison, 0. C. Freeman, S. E. Groves , 'Matrix-Dominated Performance of ThickSection Fiber Composites for Flywheel Applications', Society for the Advancement of Material and Process Engineering 2001 Symposium, Long Beach, CA., May 5-10,2001.

Hashin, Z., 1980, Failure Criteria for Unidirectional Fiber Composites. Journal of Applied Mechanics. 47, 329-334

Hine P J, R A Duckett, A S Kaddour, M J Hinton and G M Wells, 'The effect of hydrostatic pressure on some of the mechanical properties of unidirectional glass fibre /epoxy composites', Composites: Part A, V 36, 279-289, 2005.

Hinton, M.J. and Kaddour, A.S. (2009) Triaxial test results for fibre reinforced composites: Second World-Wide Failure Exercise benchmark data (WWFE-II): Part(B). QinetiQ Ltd, UK.

Kaddour, A.S. and Hinton, M.J. (2007) Instructions to contributors of the second world-wide failure exercise (WWFE-II): Part(A). QinetiQ Ltd, UK.

Kaddour A. S., Hinton M. J. and Soden P. D. (2004). Further comparison of predictive capabilities of failure theories for composite laminates', Compos Sci Techno, 64(3-4), 449-476.

Kaddour A S, Soden P D and Hinton M J,'Effects of through-thickness compressive stress on the biaxial compressive srength of $\pm 55^{\circ}$ E-glass/epoxy tubes', to be published.

Kaddour A S, Thompson L, Li, S and Hinton M J. Through-thickness compressive behaviour of carbon/epoxy laminates', to be published.

von Mises, R. Mechanik der festen Körper im plastisch deformablen Zustand. Göttin. Nachr. Math. Phys., vol. 1, pp. 582-592, 1913

Noor, A. K. and Burton, W. S., 1990. Assessment of computational models for multi-layered composite shells. Applied Mechanics Review, 43, 67-97.

Liu W, Soden P D and Kaddour A S, 'Design of end plugs for specimens under external pressures', Computers and Structures, V 83, pp976-988, 2005.

Parry T V and Wronski A S, 'Kinking and compressive failure in uniaxially aligned carbon fibre composite tested under superimposed hydrostatic pressure', J Mater Sci, V17, pp893-900, 1982.

Parry T V and Wronski A S, 'The effect of hydrostatic pressure on the tensile properties of pultruded 
CFRP', J Mater Sci, V20, pp2141-2147, 1985.

Shin E S and Pae K D, Effects of hydrostatic pressure on the torsional shear behaviour of graphite/epoxy composites, J Compos Mater, V26, pp462-485, 1992a.

Shin E S and Pae K D, Effects of hydrostatic pressure on in-plane shear properties of graphite/epoxy composites, J Compos Mater, V26, pp828-868, 1992 b.

Ye, JQ. and Zhang, D, Prediction of failure envelopes and stress strain curves of fiber composite laminates under triaxial loads. J Compos Mater (in press).

Wronski A S and Parry T V, 'Compressive failure and kinking in uniaxially aligned glass-resin composite under superimposed hydrostatic pressure', J Mater Sci, V17, pp3656-3662, 1982.

Zhang, D., Ye, J.Q. and Lam, D., 2006a. Ply cracking and stiffness degradation in cross-ply laminates under biaxial extension, bending and thermal loading. Composite Structures, 75, 121-31.

Zhang, D., Ye, J.Q. and Sheng, H., 2006b. Free-edge and ply cracking effect in cross-ply laminated composites under uniform extension and thermal loading. Composite Structures, 76, 314-25.

Zhang, D., Ye, J.Q. and Lam, D., 2007. Properties degradation induced by transverse cracks in general symmetric laminates. International Journal of Solids and Structures, 44, 5499-5517.

Zhang, D., Ye, J.Q. and Lam, D., 2008. Free-edge and Ply Cracking Effect in Angle-ply Laminated Composites subjected to In-plane Loads Journal of Engineering Mechanics, Transactions ASCE, 133(12), 1268-1277

Zinoviev PA, Tsvetkov SV, Kulish GG, van den Berg RW, Van Schepdael LJMM, 'Mechanical behaviour of high strength unidirectional composites under 3-D state of stress', Paper ID=1292, in ICCM12, Paris, France, 1999.

Zinoviev PA, Tsvetkov SV, Kulish GG, van den Berg RW, Van Schepdael LJMM, 'The behaviour of high-strength unidirectional composites under tension with superposed hydrostatic pressure', Compos Sci Technol, V61, pp 1151-1161, 2001. 


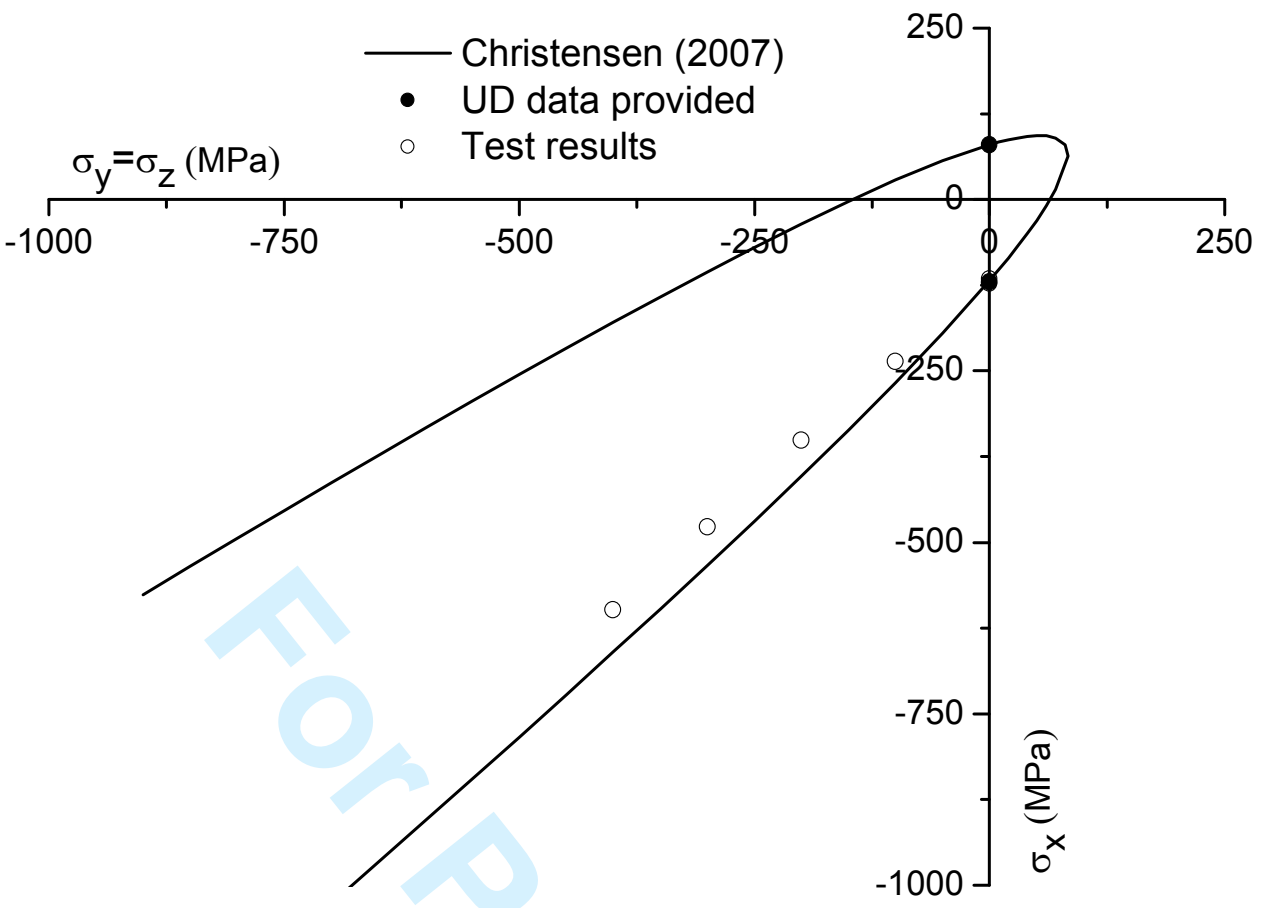

Fig. 1. Test Case 1: Variation of the Compressive strength $\left(\sigma_{\mathrm{x}}\right)$ of polymeric resin matrix with stress $\sigma_{\mathrm{y}}\left(=\sigma_{\mathrm{z}}\right)$.

Christensen (2008)

Christensen (2008), refined

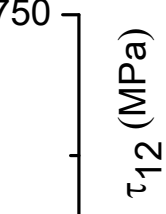

-..- Christensen (2008), reference

- Data from $90^{\circ}$ tubes

$\nabla \quad$ Data from $0^{\circ}$ tubes

500

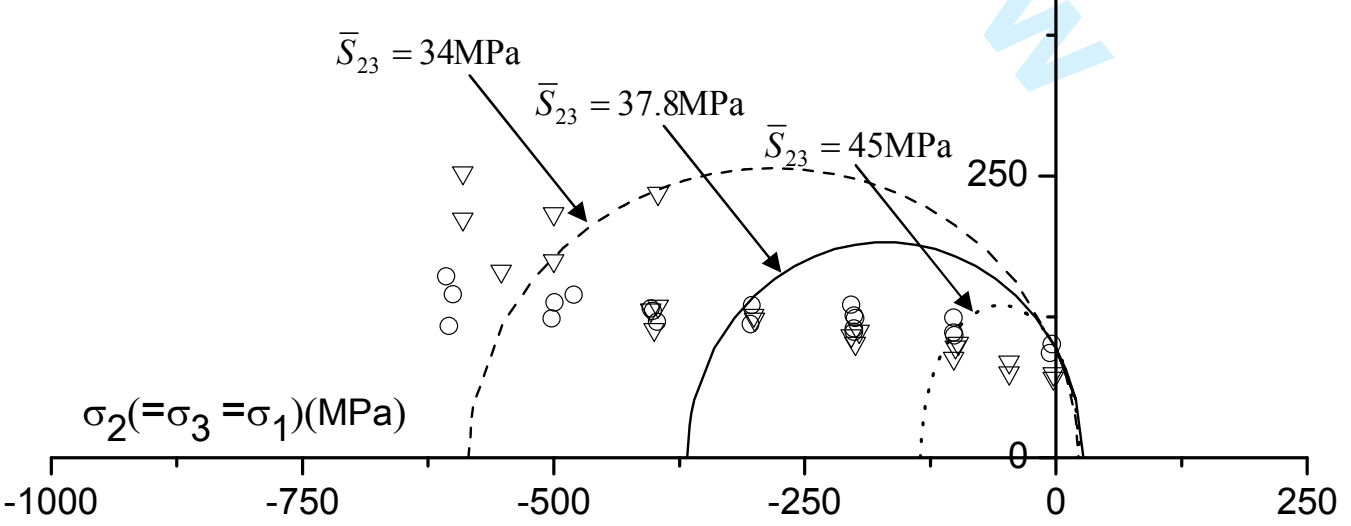

Fig. 2.Test Case 2: Variation of shear strength $\left(\tau_{12}\right)$ with stress $\sigma_{2}\left(=\sigma_{1}=\sigma_{3}\right)$ for a UD carbon/epoxy 


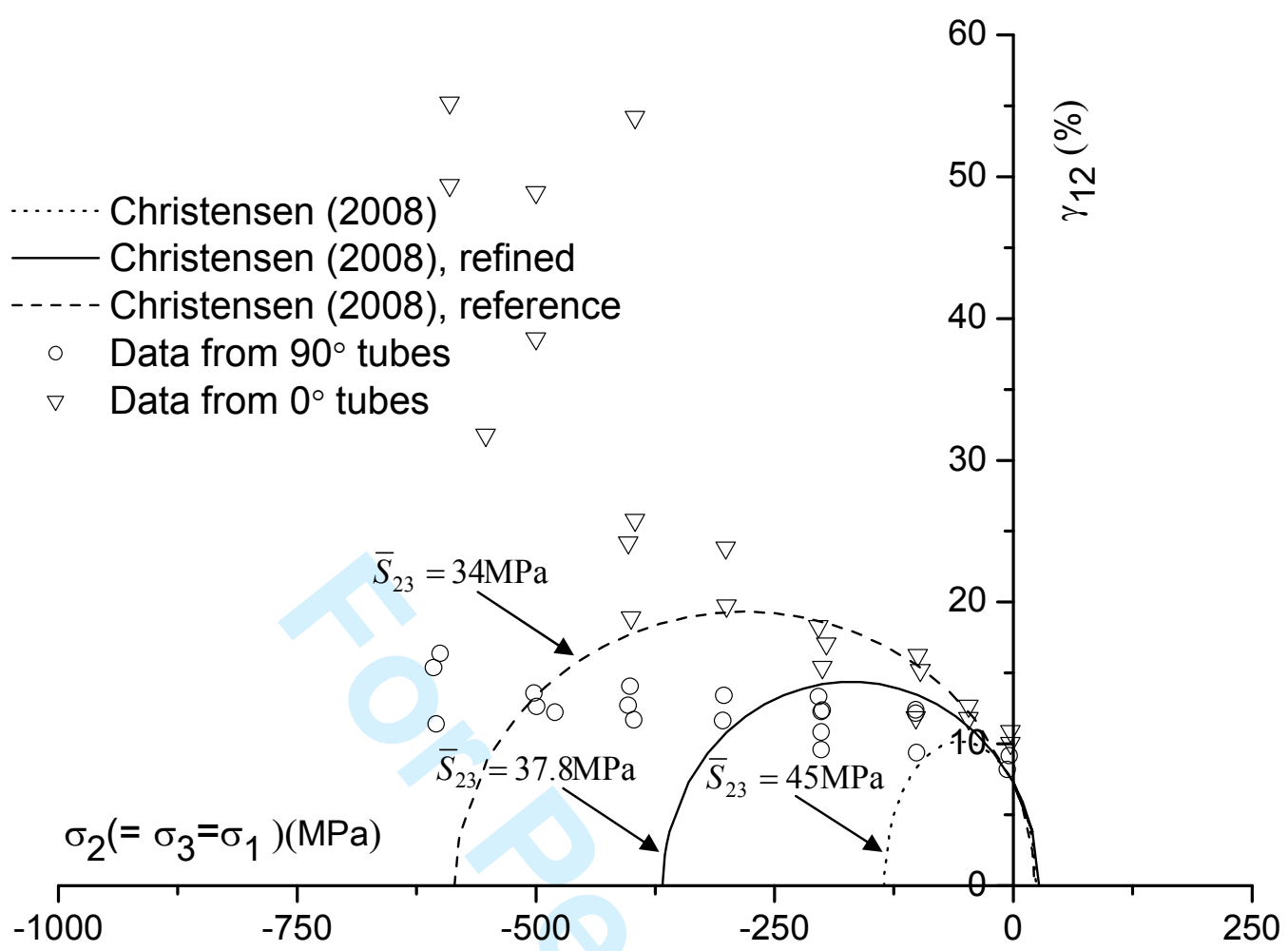

Fig. 3. Test Case 3: Variation of failure shear strain $\left(\gamma_{12}\right)$ with stress $\sigma_{2}\left(=\sigma_{1}=\sigma_{3}\right)$ for a UD carbon/epoxy

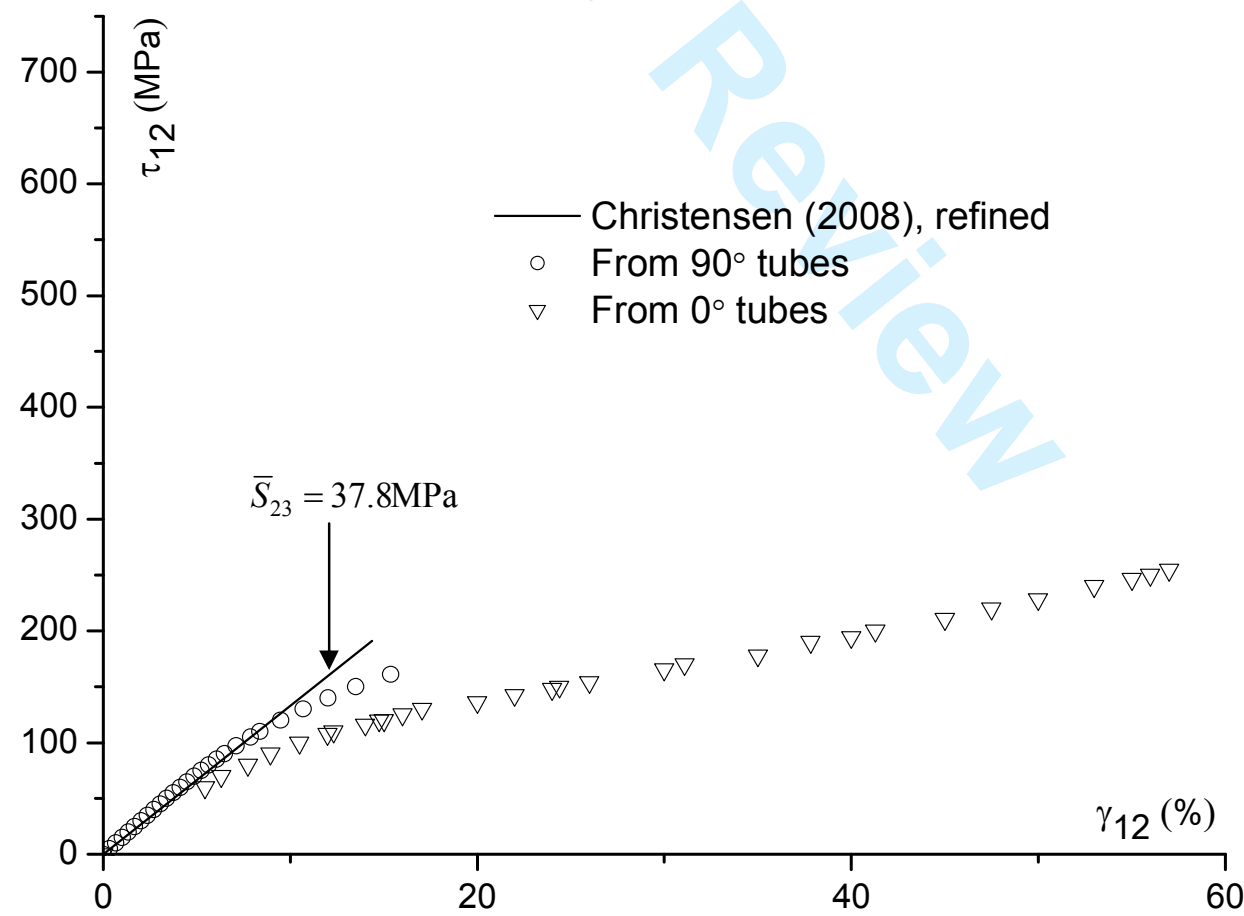

Fig. 4. Test Case 4: Shear stress strain curve $\left(\tau_{12}\right.$ versus $\left.\gamma_{12}\right)$ for a UD carbon/epoxy under hydrostatic pressure, $183.5 \mathrm{MPa} . \bar{S}_{23}=37.8 \mathrm{MPa}$. 


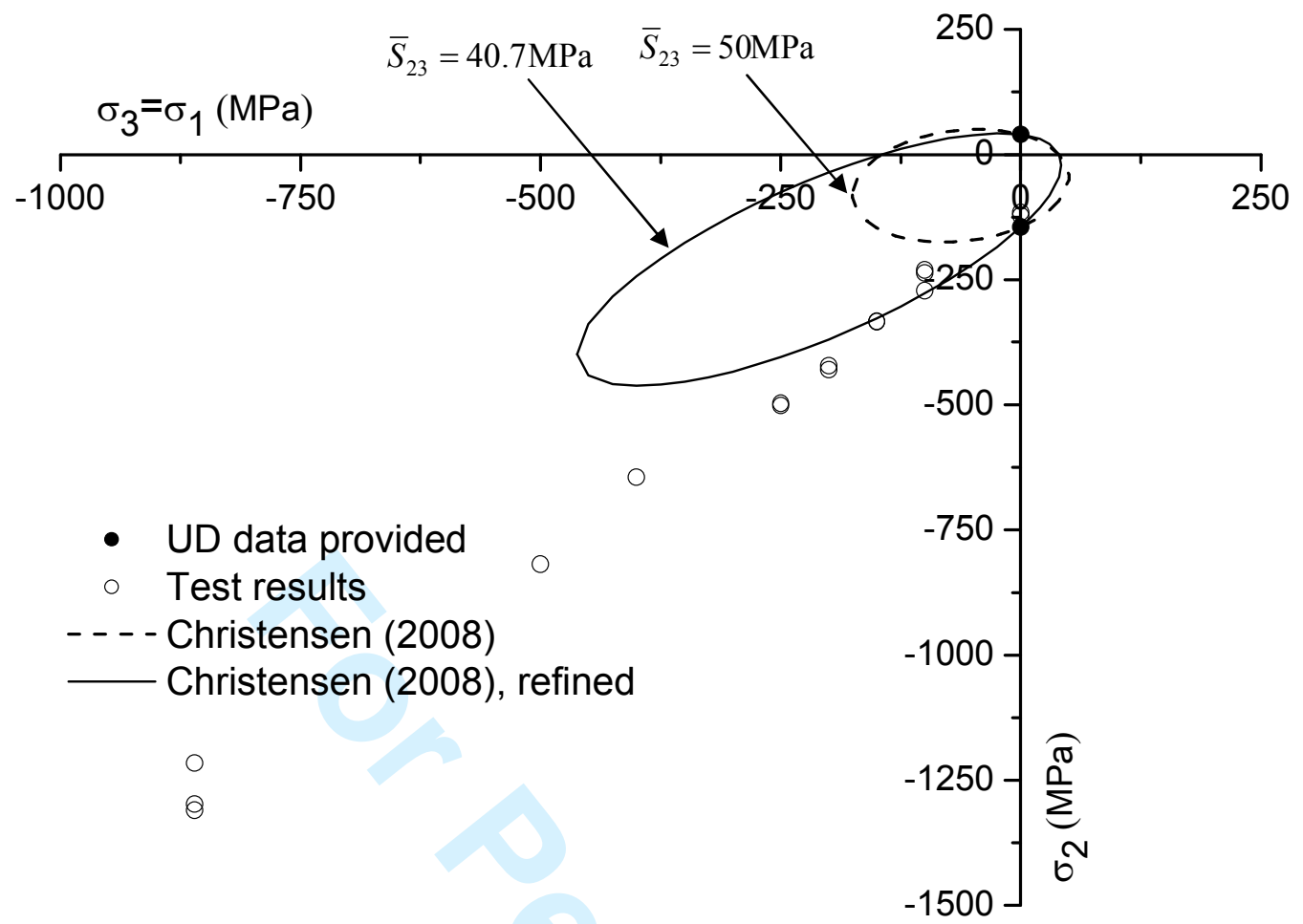

Fig. 5. Test Case 5: Variation of transverse compressive strength $\sigma_{2}$ with $\sigma_{3}$ (where $\sigma_{1}=\sigma_{3}$ ) for a UD Glass/epoxy

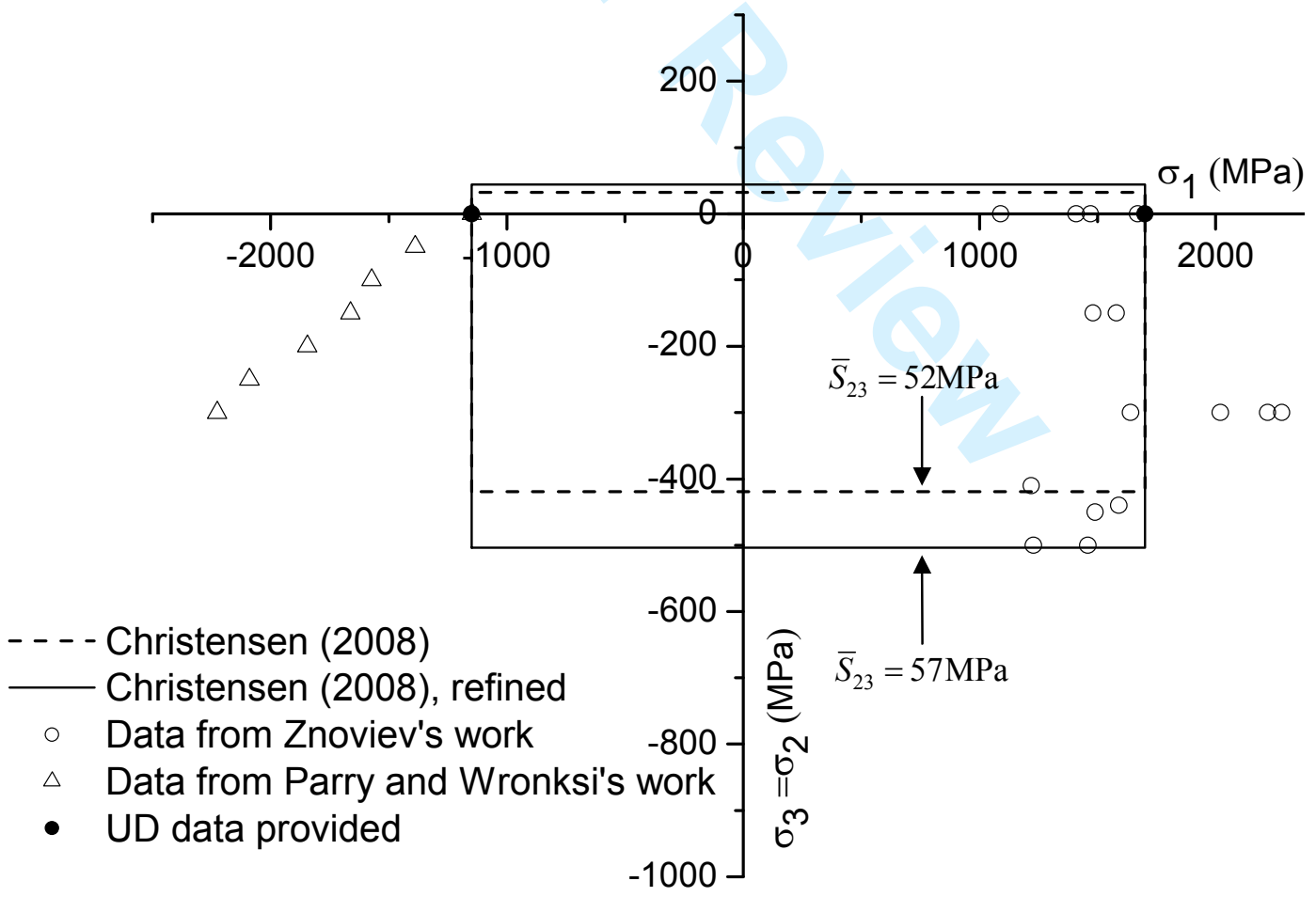

Fig. 6. Test Case 6: Variation of the longitudinal strength $\sigma_{1}$ with through-thickness stress $\left(\sigma_{3}=\sigma_{2}\right)$ for a UD glass/epoxy 
Fig. 7. Test Case 7: Variation of the longitudinal strength $\sigma_{1}$ with through-thickness stress $\left(\sigma_{3}=\sigma_{2}\right)$ for a UD Carbon/epoxy

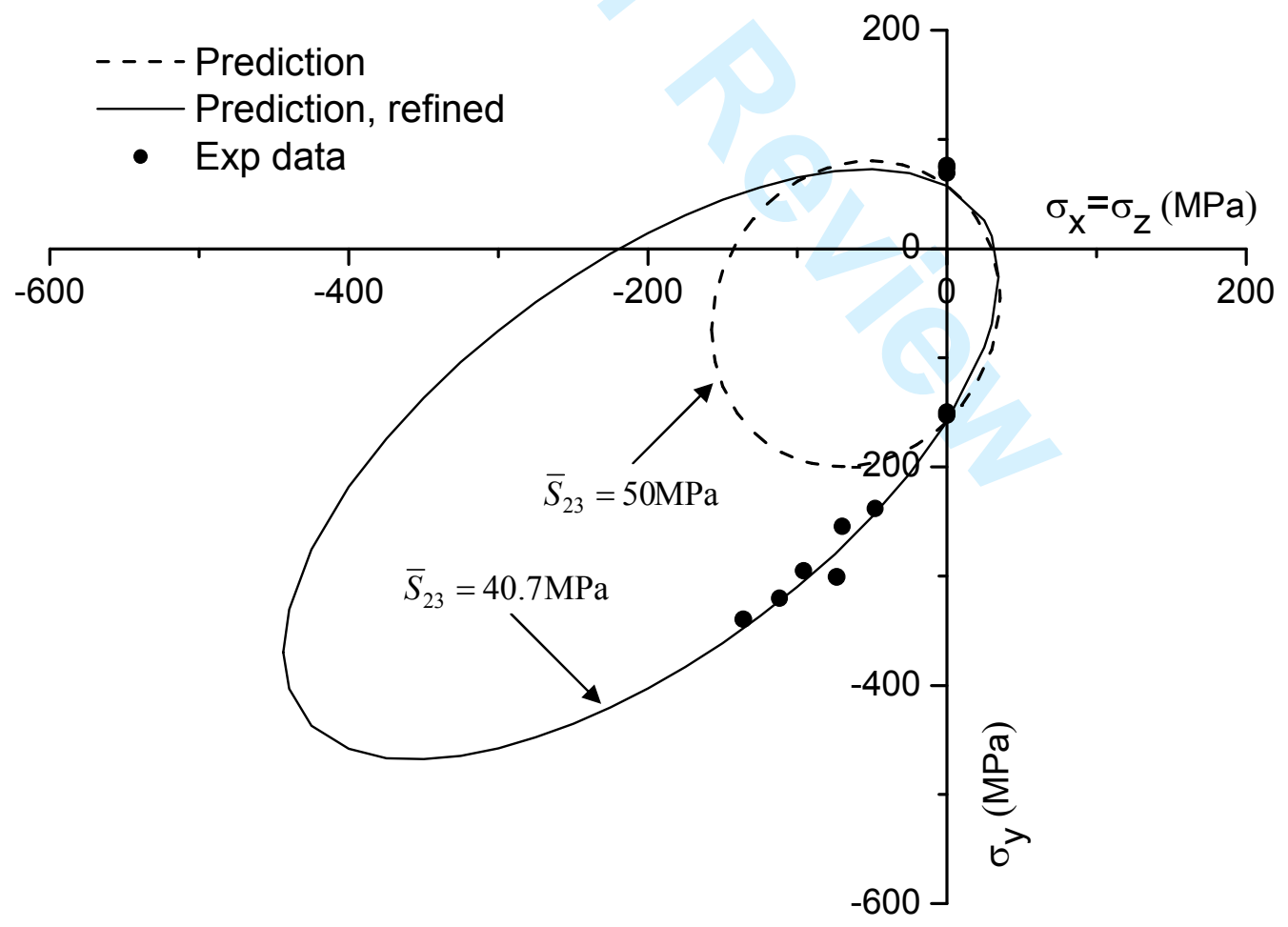

Fig. 8. Test Case 8: Variation of axial compressive strength $\sigma_{\mathrm{y}}$ with through-thickness stress $\sigma_{\mathrm{z}}$ for $(+35 /-35)_{\mathrm{s}}$ glass/epoxy laminate, where $\sigma_{\mathrm{x}}=\sigma_{\mathrm{z}}$. 


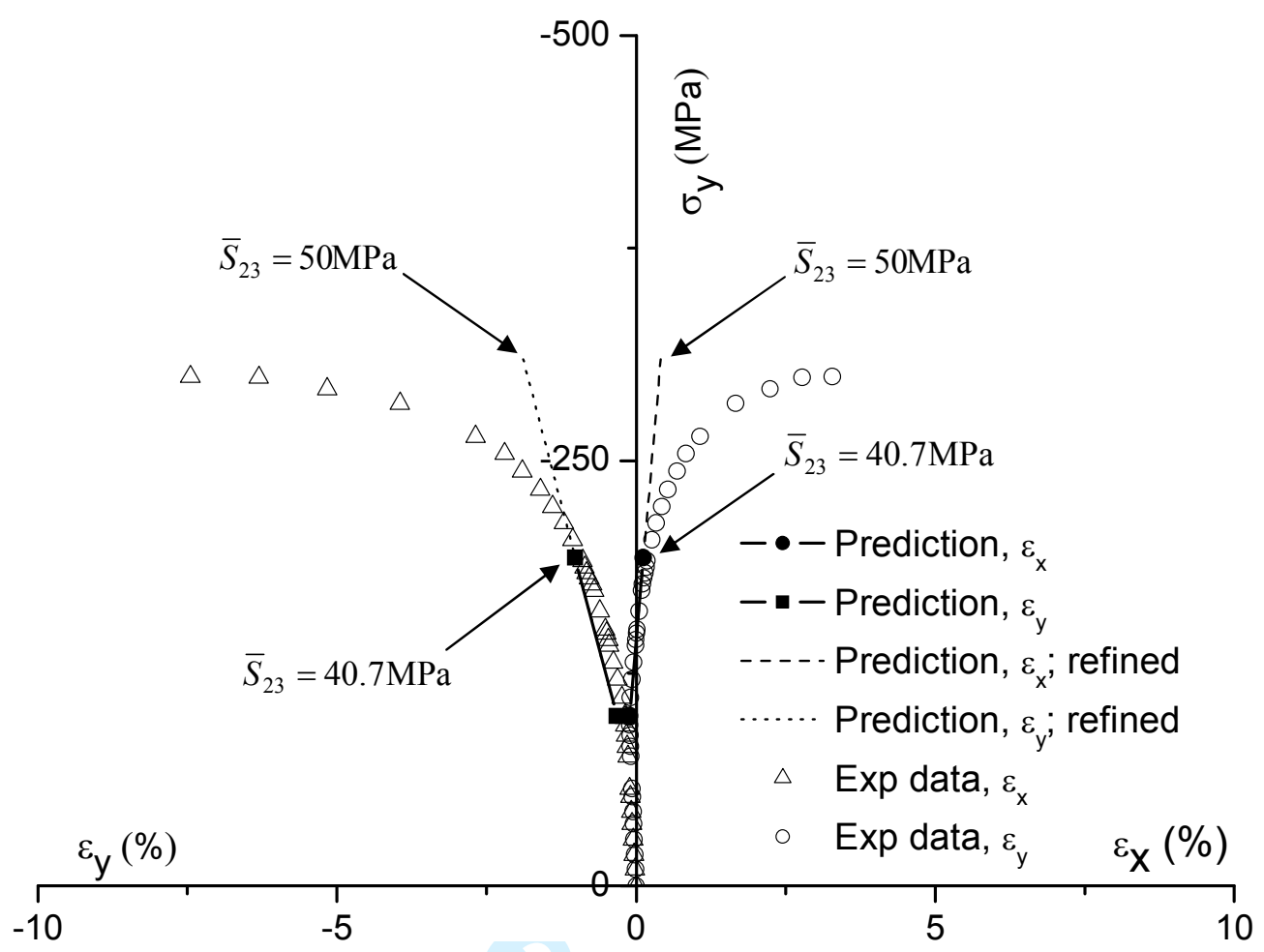

Fig. 9. Test Case 9: Axial compressive stress strain curves for $(+35 /-35)_{\mathrm{s}}$ glass/epoxy laminate under $\sigma_{\mathrm{x}}=\sigma_{\mathrm{z}}=-100 \mathrm{MPa}$.

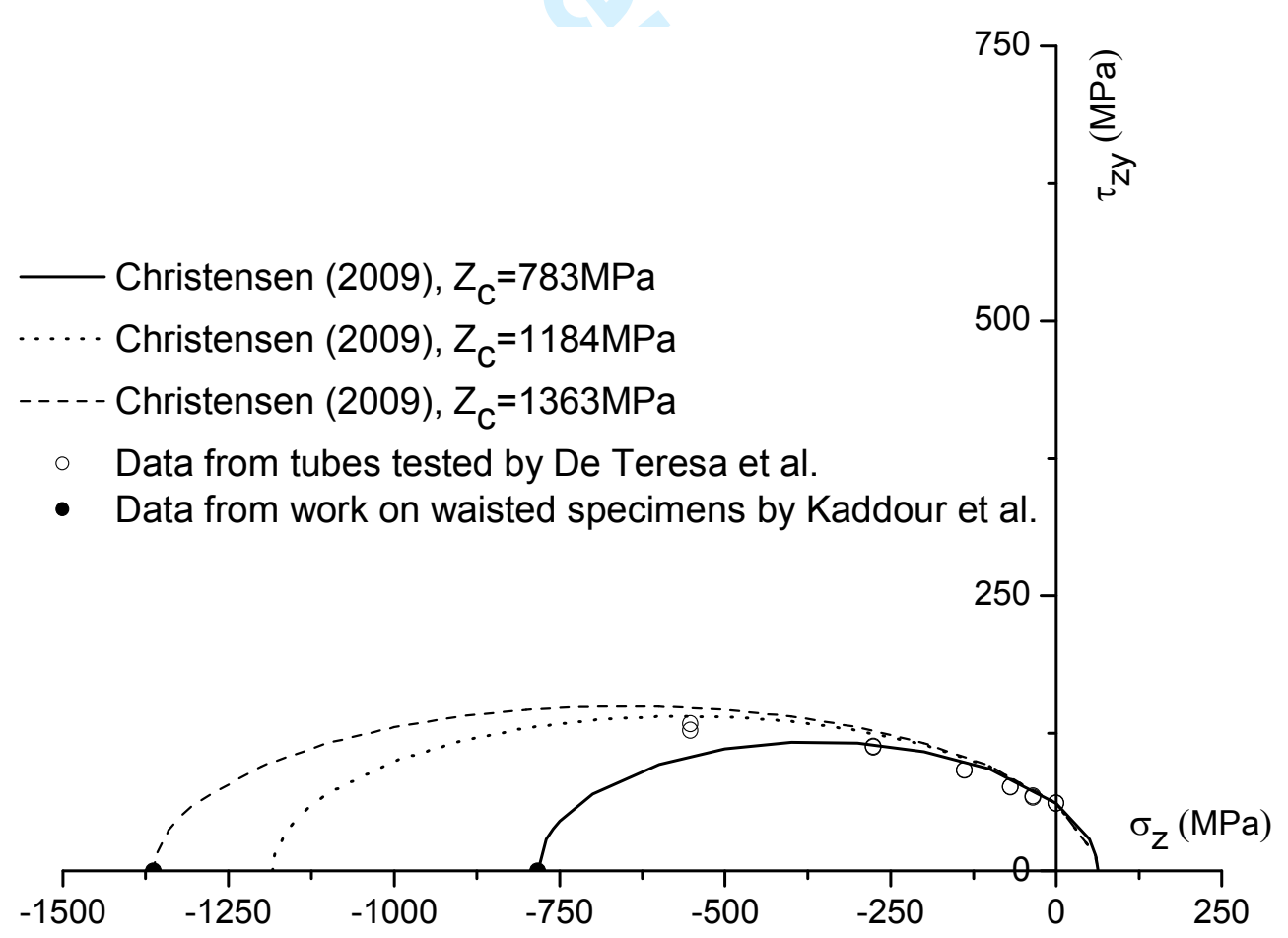

Fig. 10. Test Cases 10: Variation of shear strength $\tau_{z y}$ with through-thickness stress $\sigma_{z}$ for $(0 / 90 /+45 /-45)_{\mathrm{s}}$ carbon/epoxy laminates, with $\sigma_{\mathrm{x}}=\sigma_{\mathrm{y}}=0$. Polynomial Invariants criterion in Christensen (2009) is employed. Three values of through-thickness strength, $Z_{c}$, obtained from different specimens are used. 
Table 1 Details of the Test Cases

\begin{tabular}{llll}
\hline Test Case & Laminate lay-up & Material & Description of Required Prediction \\
\hline 1 & Resin & MY750 epoxy & $\sigma_{\mathrm{x}}$ versus $\sigma_{\mathrm{z}}\left(\right.$ with $\sigma_{\mathrm{y}}=\sigma_{\mathrm{z}}$ ) envelope \\
2 & $0^{\circ}$ & T300/PR319 & $\tau_{12}$ versus $\sigma_{2}\left(\right.$ with $\left.\sigma_{1}=\sigma_{2}=\sigma_{3}\right)$ envelope \\
3 & $0^{\circ}$ & T300/PR319 & $\gamma_{12}$ versus $\sigma_{2}\left(\right.$ with $\left.\sigma_{1}=\sigma_{2}=\sigma_{3}\right)$ envelope \\
$4(\mathrm{a})$ & $0^{\circ}$ & T300/PR319 & Shear stress strain curves $\left(\tau_{12}-\gamma_{12}\right) \quad\left(\right.$ for $\sigma_{1}=\sigma_{2}=\sigma_{3}$ \\
& & & $=-600 \mathrm{MPa})$ \\
5 & $90^{\circ}$ & E-glass/MY750 epoxy & $\sigma_{2}$ versus $\sigma_{3}\left(\right.$ with $\left.\sigma_{1}=\sigma_{3}\right)$ envelope \\
6 & $0^{\circ}$ & S-glass/epoxy & $\sigma_{1}$ versus $\sigma_{3}\left(\right.$ with $\left.\sigma_{2}=\sigma_{3}\right)$ envelope \\
7 & $0^{\circ}$ & A-S carbon/epoxy & $\sigma_{1}$ versus $\sigma_{3}\left(\right.$ with $\left.\sigma_{2}=\sigma_{3}\right)$ envelope \\
8 & $\pm 35^{\circ}$ & E-glass/MY750 epoxy & $\sigma_{\mathrm{y}}$ versus $\sigma_{\mathrm{z}}\left(\right.$ with $\left.\sigma_{\mathrm{x}}=\sigma_{\mathrm{z}}\right)$ envelope \\
$9(\mathrm{~b})$ & $\pm 35^{\circ}$ & E-glass/MY750 epoxy & Stress-strain curves $\left(\sigma_{\mathrm{y}}-\varepsilon_{\mathrm{x}}\right.$ and $\left.\sigma_{\mathrm{y}}-\varepsilon_{\mathrm{y}}\right)$ at $\sigma_{\mathrm{z}}=\sigma_{\mathrm{x}}=-100 \mathrm{MPa}$ \\
10 & $\left(0^{\circ} / 90^{\circ} / \pm 45^{\circ}\right) \mathrm{IM} 7 / 8551-7$ & $\tau_{\mathrm{yz}}$ versus $\sigma_{\mathrm{z}}\left(\right.$ with $\left.\sigma_{\mathrm{y}}=\sigma_{\mathrm{x}}=0\right)$ envelope \\
11 & $\left(0^{\circ} / 90^{\circ}\right) \mathrm{S}$ & IM7/8551-7 & $\tau_{\mathrm{yz}}$ versus $\sigma_{\mathrm{z}}\left(\right.$ with $\left.\sigma_{\mathrm{y}}=\sigma_{\mathrm{x}}=0\right)$ envelope \\
12 & $\left(0^{\circ} / 90^{\circ}\right) \mathrm{s}$ & IM7/8551-7 & Stress-strain curves $\left(\sigma_{\mathrm{z}}-\varepsilon_{\mathrm{z}}, \sigma_{\mathrm{z}}-\varepsilon_{\mathrm{x}}\right.$ and $\left.\sigma_{\mathrm{z}}-\varepsilon_{\mathrm{y}}\right)$ for $\sigma_{\mathrm{y}}=\sigma_{\mathrm{x}}=0$ \\
\hline
\end{tabular}

(a) Please first apply $\sigma_{1}=\sigma_{2}=\sigma_{3}=-600 \mathrm{MPa}$ to the lamina. Then apply the shear loading till final failure takes place.

(b) Please first apply $\sigma_{\mathrm{y}}=\sigma_{\mathrm{z}}=\sigma_{\mathrm{x}}=-100 \mathrm{MPa}$ and record the resulting strain values. Then increase the stress $\sigma_{\mathrm{y}}$ (beyond $-100 \mathrm{MPa})$ gradually till final failure takes place. Please plot the full stress-strain curves $\left(\sigma_{\mathrm{y}}-\varepsilon_{\mathrm{x}}\right.$ and $\left.\sigma_{\mathrm{y}}-\varepsilon_{\mathrm{y}}\right)$. 
Table 2 Material properties used in the present predictions

\begin{tabular}{|c|c|c|c|c|c|c|}
\hline Material & $\begin{array}{l}\text { MY750 } \\
\text { epoxy }\end{array}$ & $\begin{array}{l}\text { IM7/ } \\
8551-7\end{array}$ & $\begin{array}{l}\text { T300/ } \\
\text { PR-319 }\end{array}$ & $\begin{array}{l}\text { A-S/ } \\
\text { Epoxy1 }\end{array}$ & $\begin{array}{l}\text { S2-glass/ } \\
\text { Epoxy2 }\end{array}$ & $\begin{array}{l}\text { E-Glass/ } \\
\text { MY750 }\end{array}$ \\
\hline Longitudinal modulus $\mathrm{E}_{1}(\mathrm{GPa})$ & 3.35 & 165 & 129 & 140 & 52 & 45.6 \\
\hline Transverse modulus $\mathrm{E}_{2}(\mathrm{GPa})$ & 3.35 & 8.4 & $5.6+$ & 10 & 19 & 16.2 \\
\hline Through-thickness modulus $\mathrm{E}_{3}(\mathrm{GPa})$ & 3.35 & 8.4 & $5.6+$ & 10 & 19 & 16.2 \\
\hline In-plane shear modulus $\mathrm{G}_{12}(\mathrm{GPa})$ & 1.24 & 5.6 & $1.33+$ & 6 & 6.7 & 5.83 \\
\hline Transverse shear modulus $\mathrm{G}_{13}(\mathrm{GPa})$ & 1.24 & 5.6 & $1.33+$ & 6 & 6.7 & 5.83 \\
\hline Through-thickness shear modulus $\mathrm{G}_{23}(\mathrm{GPa})$ & 1.24 & 2.8 & 1.86 & 3.35 & 6.7 & 5.7 \\
\hline Major Poisson's ratio $v_{12}$ & 0.35 & 0.34 & 0.318 & 0.3 & 0.3 & 0.278 \\
\hline Major transverse Poisson's ratio $v_{13}$ & 0.35 & 0.34 & 0.318 & 0.3 & 0.3 & 0.278 \\
\hline Through-thickness Poisson's ratio $\mathrm{U}_{23}$ & 0.35 & 0.5 & 0.5 & 0.49 & 0.42 & 0.4 \\
\hline Longitudinal tensile strength $\mathrm{X}_{\mathrm{T}}(\mathrm{MPa})$ & 80 & 2560 & 1378 & 1990 & 1700 & 1280 \\
\hline Longitudinal compressive strength $\mathrm{X}_{\mathrm{C}}(\mathrm{MPa})$ & 120 & 1590 & 950 & 1500 & 1150 & 800 \\
\hline Transverse tensile strength $\mathrm{Y}_{\mathrm{T}}(\mathrm{MPa})$ & 80 & 73 & 40 & 38 & 63 & 40 \\
\hline Transverse compressive strength $\mathrm{Y}_{\mathrm{C}}(\mathrm{MPa})$ & 120 & 185 & 125 & 150 & 180 & 145 \\
\hline Through-thickness tensile strength $\mathrm{Z}_{\mathrm{T}}(\mathrm{MPa})$ & 80 & 63 & 40 & 38 & 50 & 40 \\
\hline Through-thickness compressive strength $\mathrm{Z}_{\mathrm{C}}(\mathrm{MPa})$ & 120 & 185 & 125 & 150 & 180 & 145 \\
\hline In-plane shear strength $\mathrm{S}_{12}(\mathrm{MPa})$ & 54 & 90 & 97 & 70 & 72 & 73 \\
\hline Transverse shear strength $\mathrm{S}_{13}(\mathrm{MPa})$ & 54 & 90 & 97 & 70 & 72 & 73 \\
\hline Through-thickness shear strength $\mathrm{S}_{23}(\mathrm{MPa})$ & 54 & 57 & 45 & 50 & 40 & 50 \\
\hline Longitudinal thermal coefficient $\alpha_{1}\left(10^{-6 /}{ }^{\circ} \mathrm{C}\right)$ & N/A & -1 & -1 & -1 & 8.6 & 8.6 \\
\hline Transverse thermal coefficient $\alpha_{2}\left(10^{-6} /{ }^{\circ} \mathrm{C}\right)$ & $\mathrm{N} / \mathrm{A}$ & 18 & 26 & 26 & 26.4 & 26.4 \\
\hline Through-thickness thermal coefficient $\alpha_{3}\left(10^{-6 /}{ }^{\circ} \mathrm{C}\right)$ & N/A & 18 & 26 & 26 & 26.4 & 26.4 \\
\hline Stress free temperature $\left({ }^{\circ} \mathrm{C}\right)$ & N/A & 177 & 120 & 120 & 120 & 120 \\
\hline
\end{tabular}

